\title{
AN ANALYSIS OF QUANTITATIVE VARIABILITY IN NICOTIANA TABACUM
}

\author{
H. F. ROBINSON, T. d. MANN and R. E. COMSTOCK \\ Institute of Statistics and Agronomy Department, North Carolina \\ Agricultural Experiment Station, Raleigh, N.C.
}

Received 3.xi.53.

Conflicting viewpoints as to the most efficient breeding procedure for improvement of quantitatively inherited characters of normally self-pollinated Nicotiana emphasise the need for information concerning the nature of the action of the genes involved. The occurrence of hybrid vigour among first generation hybrids of commercial varieties led to the suggestion of its possible use in practice by Ashton (1946). Smith (r952) favoured the procedure of developing homozygous genotypes through selection since inbreds had been obtained which were superior in many characteristics to the parents or $F_{1}$. Knowledge of the additive effects and average level of dominance of the genes controlling the expression of the characters involved would provide a basis for proper evaluation of these and other breeding techniques. The investigation reported here provides estimates of the additive genetic and dominance variance stemming from the actions of genes determining quantitative characters in inter-varietal populations of Nicotiana tabacum.

Smith (1952) and Mather (1948) have published estimates of additive genetic and dominance variance for some quantitative characters in Nicotiana rustica. Parents, $F_{1}, F_{2}$ and the two first backcrosses provided the genetic material in each of these studies. Both workers report estimates of additive genetic variance of about twice the magnitude of dominance variance for plant height. Smith studied leaf length and node number, reporting ratios of dominance to additive genetic variances of approximately $I$ to 5 and I to 4 , respectively. Apparently these are the only published reports of such information for Nicotiana.

Two procedures applicable with plants that are readily crosspollinated have been used at this station in the estimation of additive genetic and dominance variance. Robinson et al. (1949) employed biparental progenies obtained by mating plants of the $\mathrm{F}_{2}$ generation of a cross of inbred lines and Gardner et al. (I953) used similar $\mathrm{F}_{2}$ material, but obtained progenies by backcrossing each $F_{2}$ plant to both of the parent inbred lines used in the original cross. The average level of dominance for genes conditioning yield of corn have all been in the range of over dominance. No more than complete dominance

* Journal Paper 523. This research was financed in part with funds provided by the Rockefeller Foundation. 
has generally been indicated for all other characters. The possible upward bias in the dominance estimate for yield due to repulsion linkages is recognised.

Comstock and Robinson (1948) outlined the procedure used in the investigation reported here, giving the appropriate analysis of variance and genetic composition of the variance components. A comparison of the possible information and relative efficiency of this and the two schemes used with corn has been made by Comstock and Robinson (1952).

It should be pointed out that the general basis for development of the estimation procedures and interpretation of the variance of quantitative characters was provided by Fisher (1918), Fisher et al. (1932) and Wright (1935).

\section{EXPERIMENTAL PROCEDURE}

The genetic design employed in this study is applicable to multi-flowered plants whose inflorescence consists of separate florets as in Nicotiana. The $F_{2}$ generation of the four inter-varietal crosses of Nicotiana tabacum given below formed the foundation stock.

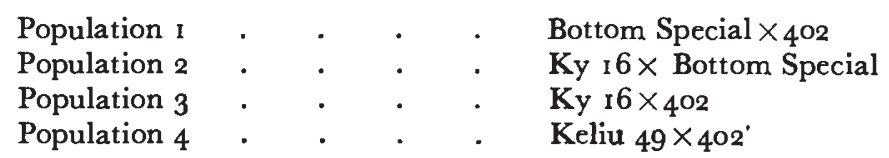

Bottom special and 402 are popular high yielding flue-cured varieties adapted to the bright-leaf tobacco producing region of North Carolina. These varieties are different in certain agronomic characteristics and contain some of the most extreme differences in traits observed in the more popular adapted varieties. 402 is a broad-leaf flue-cured type whereas Bottom Special has comparatively narrow leaves. The burley Ky 16 usually is air-cured whereas Keliu 49, grown in Charotar zone, Bombay, India, is sun-cured. The history of the source and development of these varieties is somewhat typical of tobacco varieties in general. Garner (1946) states that the historical facts of varietal origin are usually lacking but that most flue- and air-cured types can be traced to some strains of the Orinoco variety. Bottom Special is considered to be an Eastern N.C. farmer's selection whereas 402 was selected from a cross of $400 \times$ Jamaica. The variety 400 probably originated from a cross of Orinoco and White Burley, according to Garner (1946). Keliu 49 probably traces to American flue-cured types of fairly recent origin. Thus it can be seen that although varieties of very divergent type and area of adaptation were chosen for use in this study, their genetic origin may not be too different.

The $F_{2}$ plants of each population were used in groups of eight in 1949 to make $m n=16$ matings consisting of $m=4$ plants used as male parents and $n=4$ used as females. This constituted a set of material and ten such sets of 16 matings were attempted in each of the four populations. Insufficient seed for some of the crosses attempted and loss of plants in the seedling stage due to damping-off necessitated use of sets complete for $m$ and $n$ equal to either 3 or 4 in order to utilise as much of the material as possible. The field arrangement was such that each set of progenies compromised a distinct unit of the experiment and the $m n$ progenies of the set were planted in a randomised block arrangement with $r=2$ replications. The total field arrangement of material from a population consisted of $s$ independent units, each unit being a different group of $m n$ progenies of $m$ males and $n$ females. Table 1 gives the number of various size sets of progenies and the total number of crosses used in each population. 


\section{QUANTITATIVE VARIABILITY IN NICOTIANA TABACUM ${ }_{3} 67$}

The seed from each of the 579 crosses was sown on 16 th March 1950 in 8-inch pots and sufficient plants for two replications of a I2-plant plot transplanted from each pot to bands in flats as early as possible and subsequently transferred to the field. The field arrangement consisted of contiguous sets of 16,12 or 9 progenies for each population arranged in randomised blocks with two replications located at the McCullers Experiment Station, Io miles south of Raleigh, N.C.

Data were collected on the following quantitative characters : Days to flower, plant height, leaf number, leaf length and breadth, total cured leaf yield, and weight of tobacco in each grade as separated by U.S. Government tobacco grader. The days to flower was determined for each plant as the days from seeding to date of bloom of the first flower, at which time the inflorescence was removed from the plant. All height and length measurements were recorded in centimetres and weight in grams. Value per acre, a quantity reflecting both yield and quality, was computed using the 1939-4I three-year average price received for the various U.S. Government grades of all tobacco in the flue-cured region.

TABLE I

The number of $\mathrm{mn}$ sets and total $F_{2}$ sib-crosses made in four populations of tobacco

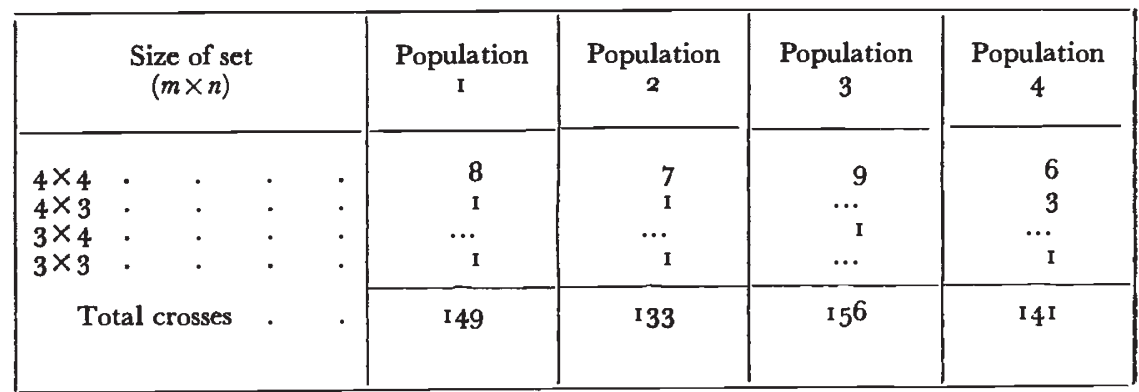

The plot values for all characters except those involving yield and quality were obtained from the data collected on Io individual competitive plants. Yield and quality determinations were made on plot totals from the same plants and all analyses utilised plot means on a per plant basis. Where less than to competitive plants occurred, plot values were based on the number of such plants available. Individual plant data from approximately every tenth plot provided estimates of "plants in plots" mean squares.

Variances in the data were analysed as shown in table 2. Genetic interpretation of the variance components arising from progeny differences in this type of an experiment have been given by Comstock and Robinson (1948) and (1952). Assumptions involved in deriving these genetic interpretations are discussed in detail with the conclusion that the assumptions most likely of questionable validity are (1) no linkage among segregating genes affecting the character in question, and (2) no epistasis, i.e. the effect of variation in the genotype at any single locus is not modified by genes at other loci. Consequences of their invalidity and some discussion of the magnitude of bias resulting from these assumptions can be obtained from Comstock and Robinson (1952). With these assumptions it can be shown that

$$
\begin{gathered}
\sigma_{m}^{2}=\sigma_{f}^{2}=\Sigma q_{i}\left(\mathrm{I}-q_{i}\right)\left[\mathrm{I}+\left(\mathrm{I}-2 q_{i}\right) a_{i}\right] \frac{u_{i}^{2}}{2}=\mathrm{I} / 4 \sigma_{g}^{2} \\
\sigma_{m f}^{2}=\Sigma q_{i}\left(\mathrm{I}-q_{i}\right) a_{i}^{2} u_{i}^{2}=\mathrm{I} / 4 \sigma_{d}^{2}
\end{gathered}
$$

where $u_{i}$ is one-half the difference in effect between the two homozygous genotypes of the $i^{\text {th }}$ segregating locus, $a_{i} u_{i}$ the deviation of the effect of the heterozygous genotype from the mean effect of the homozygous genotypes, $q_{i}$ the frequency of the favourable allele, and $\sigma_{g}^{2}$ and $\sigma_{d}^{2}$ denote additive genetic and dominance variance, 
respectively. The magnitude of $a_{i}$ measures the degree of dominance in the action of the $i^{\text {th }}$ pair of genes as follows :

$\begin{array}{ll}\text { Magnitude of } \mathrm{a}_{\mathrm{i}} & \text { Degree of dominance } \\ a_{i}=0 & \text { No dominance } \\ 0<a_{i}<\mathrm{I} \cdot 0 & \text { Partial dominance } \\ a_{i}=\mathrm{I} \cdot 0 & \text { Complete dominance } \\ a_{i}>\mathrm{I} \cdot 0 & \text { Overdominance }\end{array}$

A weighted mean of the $a_{i}^{2}$ 's, weighting being relative to the $u_{i}^{2}$ 's, is

$$
\bar{a}^{2}=\frac{\sum_{i} a_{i}^{2} u_{i}^{2}}{\sum_{i} u_{i}^{2}}=\frac{2 \sigma_{m f}^{2}}{I / 2\left(\sigma_{f}^{2}+\sigma_{m}^{2}\right)}
$$

and

$$
\bar{a}=\sqrt{\frac{2 \sigma_{m f}^{2}}{\mathrm{I} / 2\left(\sigma_{f}^{2}+\sigma_{m}^{2}\right)}}
$$

which provides a measure of the average dominance of the genes concerned if the gene frequency of the population is $1 / 2$ which was the assumption for the material used here.

\section{TABLE 2}

General form of the analysis of variance obtained from each population of $F_{2}$ sib-crosses of tobacco

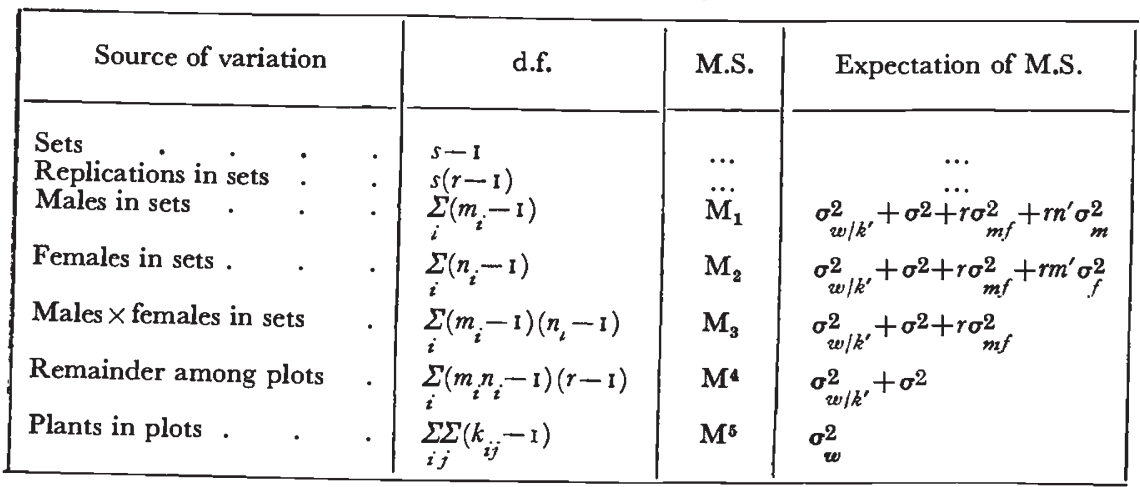

$s=$ the number of sets of progenies

$r=$ the number of replications

$m_{i}=$ the number of male parents in the $i^{\text {th }}$ set

$n_{i}=$ the number of female parents in the $i^{\text {th }}$ set

$k_{i j}=$ the number of plants in $i^{\text {th }}$ plot of the $i^{\text {th }}$ set

$m^{\prime}=\frac{\sum_{i} m_{i}\left(n_{i}-\mathrm{I}\right)}{\sum\left(n_{i}-\mathrm{I}\right)} \quad n^{\prime}=\frac{\sum_{i} n_{i}\left(m_{i}-\mathrm{I}\right)}{\sum\left(m_{i}-\mathrm{I}\right)}$

$\sigma_{w}^{2}=$ the intra-plot variance

$\sigma^{2}=$ the inter-plot error variance arising from intra-replication plot effects

$\boldsymbol{\sigma}_{m f}^{2}=$ the progeny variance due to interaction of the genotype of male and female parents

$\sigma_{f}^{2}=$ the progeny variance due to genetic differences among female parents

$\sigma_{m}^{2}=$ the progeny variance due to genetic differences among male parents 
Estimates of the variance components are obtained from the analysis in table 2 as follows :

$$
\hat{\sigma}_{m f}^{2}=4\left(M_{3}-M_{4}\right)=\hat{\sigma}_{d}^{2} .
$$

If the material in the experiment had been complete as designed, then $m=n$ and $M_{1}$ and $M_{2}$ could have been pooled since each of the mean squares have the same expectation. Since $m \neq n$ in this study, $\hat{\sigma}_{m}^{2}$ and $\hat{\sigma}_{f}^{2}$ are computed separately as

and

$$
\hat{\sigma}_{m}^{2}=\frac{\mathbf{M}_{1}-\mathbf{M}_{3}}{r n} \text { and } \hat{\sigma}_{f}^{2}=\frac{\mathbf{M}_{2}-\mathbf{M}_{3}}{r m}
$$

$$
\hat{\sigma}_{g}^{2}=2\left(\hat{\sigma}_{m}^{2}+\hat{\sigma}_{f}^{2}\right) \text {. }
$$

Covariance analyses between all pairs of characters, similar to that illustrated for the variance analysis in table 2, were computed and from these the completely analogous covariance components were estimated.

TABLE 3

\begin{tabular}{|c|c|c|c|c|}
\hline $\begin{array}{l}\text { Character } \\
\text { studied }\end{array}$ & $\begin{array}{c}\text { Population } \\
\text { I }\end{array}$ & $\begin{array}{l}\text { Populations } \\
2 \text { and } 3\end{array}$ & $\begin{array}{c}\text { Population } \\
4\end{array}$ & $\begin{array}{l}\text { Populations } \\
\text { combined }\end{array}$ \\
\hline $\begin{array}{l}\text { Days to flower } \\
\text { Plant height } \\
\text { Leaf number } \\
\text { Leaf length } \\
\text { Leaf breadth } \\
\text { Leaf yield } \\
\text { Leaf value }\end{array}$ & $\begin{array}{c}2 \cdot 50 \pm 0 \cdot 67 \\
39 \cdot 83 \pm 1 \mathrm{r} \cdot 48 \\
0 \cdot 5782 \pm 0 \cdot 2 \mathrm{r} 1 \\
\mathrm{r} \cdot 8694 \pm 0 \cdot 6630 \\
3 \cdot 7 \mathrm{r} 98 \pm \mathrm{r} \cdot \mathrm{r} 494 \\
44 \cdot 50 \pm 14 \cdot 84 \\
66 \mathrm{r} \cdot 95 \pm 24 \mathrm{r} \cdot 22\end{array}$ & $\begin{array}{c}4 \cdot 49 \pm \mathrm{r} \cdot \mathrm{I} 5 \\
46 \cdot 54 \pm \mathrm{r} 3 \cdot 60 \\
0 \cdot 88 \mathrm{r} 4 \pm 0 \cdot 1800 \\
0 \cdot 8966 \pm 0 \cdot 5589 \\
2 \cdot 0590 \pm 0 \cdot 5 \mathrm{Ir} 9 \\
49 \cdot 19 \pm 15 \cdot 34 \\
890 \cdot 10 \pm 266 \cdot 8 \mathrm{r}\end{array}$ & 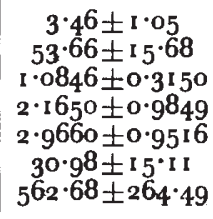 & $\begin{array}{c}3 \cdot 72 \pm 0 \cdot 6 \mathrm{r} \\
46 \cdot 40 \pm 8 \cdot 02 \\
0 \cdot 8526 \pm 0 \cdot 1296 \\
\mathrm{r} \cdot 46 \pm 0 \cdot 3934 \\
2 \cdot 70 \pm 0 \cdot 4354 \\
43 \cdot 58 \pm 9 \cdot 14 \\
744 \cdot 97 \pm \mathrm{r} 57 \cdot 34\end{array}$ \\
\hline$g^{\prime}$ & $\left\{\frac{2\left(\mathrm{M}_{1}\right)^{2}}{\sum_{i}\left(m_{i}-\mathrm{I}\right)}+\right.$ & $\frac{2\left(\mathrm{M}_{3}\right)^{2}}{\left.a_{i}-\mathrm{I}\right)\left(n_{i}-\mathrm{I}\right)}$ & 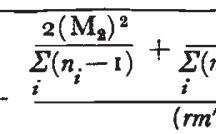 & $\frac{2\left(M_{3}\right)^{2}}{\left.n_{i}-I\right)\left(n_{i}-I\right)}$ \\
\hline
\end{tabular}

Estimates of the additive genetic variance, $\hat{\sigma}_{g}^{2}$, and their standard errors calculaud for various characters in tobacco *

\section{RESULTS}

Tables 3 and 4 present the estimates of additive genetic variance, $\hat{\sigma}_{g}^{2}$, and dominance variance, $\hat{\sigma}_{d}^{2}$, respectively. Since populations 2 and 3 both involve the two flue-cured parents crossed to the same burley variety, Ky 16 , combined estimates from these populations are presented.

The marked morphological differences between parental varieties involved in the flue-cured $\times$ burley and flue-cured $\times$ Indian Sun-cured populations suggested the possibility of more genetic variability among the segregating progenies from these populations than among progenies derived from crossing two flue-cured varieties widely grown in the same region of adaptation. The results are not in accord with this expectation. The estimates of additive genetic variance are quite similar for all characters for the three groupings of genetic material. The standard errors associated with each of the estimates provide a basis for evaluating the reliability of these estimates, but 
are not exact when used for setting fiducial limits. The fiducial limits about these estimates are not symmetrical but will generally be higher than the lower or upper limits indicated by use of these standard errors. Approximately double the number of progenies is involved in the combined estimates calculated for populations 2 and 3 , resulting in smaller standard errors than those obtained for individual populations. Combining all material reduces the standard errors to approximately one-third to one-fourth the estimated $\sigma_{g}^{2}$.

The magnitude of the dominance variance estimates is strikingly different from the additive genetic variances. Nineteen of the twentyeight " males $\times$ females in sets" mean squares $\left(\mathbf{M}_{3}\right.$, table 2) were smaller than the error mean square although the expectation of $\mathbf{M i}_{3}$

TABLE 4

Estimates of the dominance variance, $\hat{\sigma}_{d}^{2}$, and their standard errors calculated for various characlers in tobacco *

\begin{tabular}{|c|c|c|c|c|}
\hline $\begin{array}{l}\text { Character } \\
\text { studied }\end{array}$ & $\begin{array}{c}\text { Population } \\
1\end{array}$ & $\begin{array}{l}\text { Populations } \\
2 \text { and } 3\end{array}$ & $\begin{array}{c}\text { Population } \\
4\end{array}$ & $\begin{array}{l}\text { Populations } \\
\text { combined }\end{array}$ \\
\hline $\begin{array}{l}\text { Days to flower } \\
\text { Plant height } \\
\text { Leaf number } \\
\text { Leaf length } \\
\text { Leaf breadth } \\
\text { Leaf yield } \\
\text { Leaf value }\end{array}$ & $\begin{array}{c}0.53 \pm 0.76 \\
(-17.30 \pm 14.86) \\
(-0.1170 \pm 0.4308) \\
0.5160 \pm 1.1552 \\
(-1.0678 \pm 1 \cdot 7280) \\
(-55.84 \pm 29.53) \\
(-899.41 \pm 510.68)\end{array}$ & $\begin{array}{c}0.34 \pm 1.91 \\
8.61 \pm 24.87 \\
0.0468 \pm 0.2400 \\
0.4892 \pm 1.5616 \\
0.3048 \pm 0.8680 \\
(-16.06 \pm 34.17) \\
(-240.35 \pm 569.92)\end{array}$ & $\begin{array}{c}(-2 \cdot 13 \pm 1 \cdot 64) \\
(-8 \cdot 53 \pm 21 \cdot 99) \\
(-0.3760 \pm 0.4560) \\
(-0.0110 \pm 2 \cdot 1008) \\
0.4844 \pm 1 \cdot 3780 \\
(-33 \cdot 11 \pm 36 \cdot 34) \\
(-426 \cdot 95 \pm 652 \cdot 00)\end{array}$ & $\begin{array}{c}(-0.22 \pm 0.96) \\
(-2.46 \pm 13.29) \\
(-0.0964 \pm 0.1960) \\
0.3^{6} \pm 0.9484 \\
(-0.02 \pm 0.6984) \\
(-30.68 \pm 20.19) \\
(-459.97 \pm 344.52)\end{array}$ \\
\hline
\end{tabular}

$$
\text { * S.E. } \sigma_{d}^{2}=\sqrt{\frac{\frac{2\left(\mathrm{M}_{3}\right)^{2}}{\sum_{i}^{\left(m_{i}-\mathrm{I}\right)\left(n_{i}-1\right)}+\sum_{i}\left(m_{i} n_{i}-1\right)(r-1)}}{r^{2}}}
$$

contains the additional dominance variance component. An indication of the variability of estimates of $\sigma_{d}^{2}$, computed from both negative and positive components of variance, is provided by the values in table 4. In no case did the negative values deviate sufficiently from zero by more than was accounted for by sampling variation as shown by the standard errors. The only biological explanation offered for the high number of negative variance components is the possible existence of negatively correlated effects between adjacent plots. In the cases of yield and value determinations, no positive components of variance were found for any of the populations. All other characters in the flue-cured-burley populations did provide some indication of dominance variance but here the standard errors are larger than the estimates in every case. The estimate of $\sigma_{d}^{2}$ from all populations combined is positive only for leaf length; however, the associated standard error indicates this may be no different from zero. The null hypothesis of no dominance variance was tested from the analyses of variance in terms of $F=M_{3} / M_{4}$. In no case was the $F$ significant 
at the 0.05 probability level. Thus the data provide no statistically significant evidence for dominance at any level.

The presence of additive genetic variance indicates that selection among these populations should be effective. Let $\mathrm{G}_{s}$ be the expected difference in mean genotypic merit between a population obtained by random interbreeding among selected progenies and the population in which selection was practised. This difference may be taken as a measure of the expected effect of selection and can be expressed as

$$
\mathrm{G}_{s}=\mathrm{K} \sigma_{c} \frac{\sigma_{y}^{2}}{\sigma_{c}^{2}}=\frac{\mathrm{K} \sigma_{y}^{2}}{\sigma_{c}}
$$

where, for the character under selection,

$\sigma_{y}^{2}=$ the additive genetic variance among selection units; $\mathbf{I} / \mathbf{2} \sigma_{g}^{2}$ in the case of these full-sib progenies,

$\sigma_{c}^{2}=$ phenotypic variance among progeny values on which selection is based (for selection among these progenies based on the means for plots in two replications

$$
\sigma_{c}^{2}=\frac{\sigma_{w / k}^{2}+\sigma^{2}}{r}+\sigma_{m f}^{2}+\sigma_{m}^{2}+\sigma_{f}^{2}
$$

$\mathrm{K}=$ the selection differential in multiples of $\sigma_{c}$.

$\mathrm{It}$ is frequently desirable to compute $\mathrm{G}_{s}$ as a percentage of the population mean. For this purpose we can write

$$
\frac{(\mathrm{IO0}) \mathrm{G} s}{\bar{x}}=\frac{(\mathrm{IO0}) \mathrm{K} \sigma_{y}^{2}}{\bar{x} \sigma_{c}}=\mathrm{K}\left(\frac{\mathrm{IOO} \sigma_{y}}{\bar{x}}\right)\left(\frac{\sigma_{y}}{\sigma_{c}}\right)
$$

Note that if the only variance among progeny values were that represented in $\sigma_{y}^{2}$, i.e. if $\sigma_{c}^{2}=\sigma_{y}^{2}$, expected progress, under constant selection intensity as represented by $K$, would depend only on (Ioo $\sigma_{y} / \vec{x}$ ). Burton (1952) defined the latter as the genetic coefficient of variability and (recognising that $\sigma_{y} / \sigma_{c} \leqslant \mathrm{I} \cdot 0$ ) pointed out that it reflects the limit in progress from selection in a single generation that can be approached through minimising the non-genetic portion of $\sigma_{c}^{2}$. Genetic coefficients of variability for full-sib progenies are presented in table 5 . They were computed as

$$
100 \sqrt{\frac{\hat{\sigma}_{g}^{2} / 2}{\bar{x}}}
$$

using estimates of $\sigma_{g}^{2}$ from table 3 . Also presented in table 5 are estimates (computed in terms of equation 2) of progress from selection among the full-sib progenies in terms of means for the two replications used in the study. $\mathrm{K}$ was set equal to $2 \cdot 06$, its expected value assuming 5 per cent. selection from a large sample out of a normally distributed population of progenies. In view of population-to-population consistency in estimates of $\hat{\sigma}_{g}^{2}$ (table 3 ) only values obtained using the combined data of all four populations are presented.

Values for estimated progress range from about equal to about 40 per cent. greater than the corresponding coefficient of genetic 
variability. Since they would have been $2 \cdot 06$ times as large assuming equality of $\sigma_{y}^{2}$ and $\sigma_{c}^{2}$, this reflects the fact that values of $\sqrt{\sigma_{y} / \sigma_{c}}$ were in the range 0.49 to 0.68 .

\section{DISCUSSION}

Any interpretation of these results must be conditioned by the possible bias due to genotypes giving differential response due to environmental changes. Since this study was conducted in only one location and year, variance due to interaction of genotypes with the environment of the particular location and year involved would contribute to the apparent genetic variance and the estimates of the latter are correspondingly biased as measures of variance in genotypic merit with respect to the whole population of environments for which improvement in the crop is desired. It follows that the estimates of

TABLE 5

Genetic coefficients of variability and estimates of progress for various characters with all populations combined

\begin{tabular}{|c|c|c|c|c|}
\hline \multicolumn{3}{|c|}{$\begin{array}{l}\text { Character } \\
\text { studied }\end{array}$} & $\begin{array}{c}\text { Genetic } \\
\text { C.V. }\end{array}$ & $\begin{array}{c}\text { Estimates of } \\
\text { progresss }\end{array}$ \\
\hline $\begin{array}{l}\text { Days to flower } \\
\text { Plant height } \\
\text { Leaf number } \\
\text { Leaf length } \\
\text { Leaf breath } \\
\text { Leaf yield } \\
\text { Leaf value }\end{array}$ & . & • & $\begin{array}{l}1 \cdot 03 \\
3 \cdot 25 \\
2 \cdot 93 \\
1 \cdot 55 \\
3 \cdot 59 \\
4 \cdot 60 \\
5 \cdot 44\end{array}$ & $\begin{array}{l}1 \cdot 40 \\
4 \cdot 31 \\
4 \cdot 12 \\
1 \cdot 56 \\
4 \cdot 93 \\
5 \cdot 09 \\
6 \cdot 04\end{array}$ \\
\hline
\end{tabular}

progress through selection may also be biased upward. The data provide no information on the possible magnitude of variance due to interaction of genotype with location and year. Results obtained at this institution with other crops (largely unpublished) suggest that at most it probably does not exceed that of the actual genetic variance.

While an expected advance of about 5 per cent. from selection among these progenies for leaf yield is suggested, there can be no guarantee that comparable gains could also be made in following generations. It is to be expected that improvement rate will decline as selection is continued. On the other hand unless the number of genes involved is considerably smaller than ordinarily assumed for such quantitative characters it would appear entirely possible that as much as 15 or 20 per cent. improvement might be effected by continuing selection over several generations, selected progenies in each generation being interbred (rather than selfed) to yield the next generation. Such a conclusion is strongly supported by the coefficient of genetic variation when computed on the basis of single plants rather than progenies. For example, for leaf yield it is found to be 6.5 per cent. This suggests that there were plants in these 
populations that were as much as 15 per cent. superior in genotype (2.5 standard deviations above the mean) to the population average and hence that an entire population equally as good is not impossible. The results for leaf size characters indicate that much more rapid progress is possible in these populations when selecting for strains with broader leaves than for strains having longer leaves.

The genetic correlations among characters become of extreme practical importance when the economic evaluation of a crop depends upon two or more traits. This is especially true of tobacco where improvement in yield must be accompanied by acceptable quality. The genetic correlation among all pairs of characters were determined but only those computed from the population developed from crossing flue-cured varieties and pertinent to this discussion will be mentioned.

These genetic relationships indicate that selecting higher yielding progenies from this population will, on the average, result in concurrent improvement in all yield components studied-plant height,

TABLE 6

Genetic correlations between leaf yield and other characters in population I

\begin{tabular}{|c|c|c|c|c|c|}
\hline $\begin{array}{c}\text { Days to } \\
\text { flower }\end{array}$ & $\begin{array}{c}\text { Plant } \\
\text { height }\end{array}$ & $\begin{array}{c}\text { Leaf } \\
\text { number }\end{array}$ & $\begin{array}{c}\text { Leaf } \\
\text { length }\end{array}$ & $\begin{array}{c}\text { Leaf } \\
\text { breadth }\end{array}$ & $\begin{array}{c}\text { Leaf } \\
\text { value }\end{array}$ \\
\hline 0.1280 & 0.2980 & 0.6083 & $0.4 .4^{19}$ & 0.4897 & $1 \cdot 0042$ \\
\hline
\end{tabular}

leaf number and leaf size. The expected progress in leaf yield when the superior 5 per cent. of the progenies are selected on the basis of high leaf number was computed to be 62 per cent. as much yield improvement as when selection was for yield itself. The basis of computation has been given by Robinson and Comstock (I952). This is a practical illustration of the possible usefulness of information on the genetic relationships between characters. Selection would be indirectly for higher yield but based on leaf count, a more readily determined value. The magnitude of this relationship was not consistent for all populations, being quite low for population 4. This indicates that maximum progress from selecting for two or more characters simultaneously must be based upon a knowledge of the genetic inter-relationships of the characters for the specific material involved. A very high genetic correlation between yield and value is noted in table 6 and this same relationship existed in the other populations. It is not suggested that this would be universally true in such populations from variety crosses within Nicotiana tabacum. Should tobacco varieties with sufficiently different attributes of quality be involved as parents of such populations, this genetic correlation may be considerably reduced. Furthermore, it is not implied from these results that better quality tobacco is associated with the higher yielding progenies. Actually the price per hundred pounds of tobacco 
decreased as yield increased in all of the populations. Nevertheless, these results indicate that selection for yield among progenies of segregating populations developed from parental varieties with acceptable quality characteristics need not be subjected in the early stage of strain development to the expensive procedure of curing and grading for the purpose of arriving at a "value" rating. The additional effort and cost can probably best be used in evaluating more progenies for yield under different environmental conditions.

The low estimates of any dominance effects in the action of the genes conditioning the expression of the various characters is of particular importance in the consideration of breeding procedures. Since epistatic effects would contribute to dominance variance estimates it is further assumed that they too are relatively unimportant in the action of genes considered in these populations. Furthermore, recognising that high frequency of repulsion phase linkage is a possible source of upward bias in the dominance variance, assuming dominance is associated with the favourable allele only, gives additional support to the evidence of negligible dominance. Smith (r953) came to the same general conclusions from results obtained in Nicotiana rustica, even though more dominance was reported than was obtained in this study. However, when the sampling errors attached to his estimates are considered, in no case was dominance variance significantly different from zero. The observation of appreciable heterosis in $\mathrm{F}_{1}$ hybrids of Nicotiana tabacum variety crosses is contrary to expectation based on the degree of dominance indicated in this study. Patel (1949) compared the $\mathrm{F}_{1}$ with mid-parent values for the same populations used in this study and reported heterosis to the extent of 2 and 6 per cent. for leaf yield and plant height respectively. Mann (unpublished) tested six flue-cured varieties and the 15 possible $\mathrm{F}_{1}$ hybrids at three locations in 1952 and found a 2.5 per cent. difference in yield in favour of hybrids which was non-significant. The low amount of heterosis suggests at least some degree of dominance but probably low in view of these results and in accord with Smith's conclusion.

\section{SUMMARY}

This investigation provides estimates of the additive genetic and dominance variance in four $\mathrm{F}_{2}$ populations developed from intervarietal crosses in Nicotiana tabacum. The scheme for producing the experimental progenies is appropriate with plants with multiple inflorescence which requires a set of $m n$ crosses among sets of $m$ individuals used as male parents with $n$ female parents.

The results indicate that little dominance is concerned in the action of genes conditioning the inheritance of the characters considered. The low magnitude of the estimates of dominance variance indicates little effect from epistasis which would tend to produce upward bias. The estimates of additive genetic variance were of 
sufficient magnitude to suggest appreciable progress in the improvement of most of the characters studied from selecting among the progenies.

Genetic coefficients of variability were computed and inferences made from these as to the limit of progress from selection. Indications are that approximately 15 per cent. advance in leaf yield could be effected by creating a new population from the most superior genotype.

Genetic correlations between leaf yield and several other characters in population I are presented and implications given of the consequences of such relationships on practical breeding problems. The extremely high positive genetic correlation between leaf yield and value of cured leaf is the basis for suggesting that determination of the latter trait could be omitted in breeding work with certain material.

The limitations of these results are emphasised with respect to possible bias from genotype-environmental interactions. If these interactions are important the estimates obtained in this study under one environment may not provide a realistic appraisal of rate of improvement possible. However, assuming them to be applicable for other environments and for similar type populations of Nicotiana tabacum it is concluded that a breeding procedure designed to accumulate the maximum number of favourable genes in homozygous genotypes should offer more promise for tobacco improvement than attempting to utilise $F_{1}$ hybrids on a commercial scale. The possibility of about ro per cent. improvement in yield above the population mean is suggested from developing true breeding strains from selfing and selecting in this material. Additional progress can only result from recombination of selected genotypes.

\section{BIBLIOGRAPHY}

Ashton, T. 1946. The use of heterosis in the production of agricultural and horticultural crops. Imper. Bur. Plant Breed. and Genetics, School of Agric., Cambridge, $30 \mathrm{pp}$.

Burton, GLENN W. 1952. Quantitative inheritance in grasses. Proc. Sixth International Grassland Congress, I, 297-283. Pa. State College, Aug. 17-23. National Publishing Company, Washington, D.C.

COMSTOCK, R. E., AND ROBINSON, H. F. 1948. The components of genetic variance in population of biparental progenies and their use in estimating the average degree of dominance. Biometrics, 4, 254-266.

COMSTOCK, R. E., AND ROBINSON, H. F. 1952. Estimation of the average dominance of genes. Heterosis, pp. 494-516. Ames, Iowa, Iowa State College Press.

FISHER, R. A. I9I8. The correlation between relatives on the supposition of Mendelian inheritance. Trans. Roy. Soc. Edinb., 52, 399-433.

FISHER, R. A., IMMER, F. R., AND TEDIN, O. I932. The genetical interpretation of statistics of the third degree in the study of quantitative inheritance. Genetics, 17, 107-1 24 .

GARDNER, G. O., HARVEY, P. H., GOMSTOCK, R. E., AND ROBINSON, H. F. I953. Dominance of genes controlling quantitative characters in maize. Agron. Jour., 45, I 86-igi.

GaRner, w. w. 1946. The production of Tobacco. $5^{16}$ pp. The Blakiston Co., Phila., $\mathrm{Pa}$. 


\section{H. F. ROBINSON, T. J. MANN AND R. E. COMSTOGK}

MATHER, K. 1948. The genetical theory of continuous variation. Proc. Eighth International Congress of Genetics, pp. 376-401. Suppl. Vol. of Hereditas.

PATEL, M. S. 1949. Genetic variability in Nicotiana tabacum. Ph.D. thesis, N.C. State College Library.

ROBINSON, H. F., AND COMSTOCK, R. E. 1952. The place of genetic variability studies in cotton improvement. Proc. Fifth Cotton Improvement Conference, N.C. State College, Raleigh, N.C., Sept. II.

ROBINSON, H. F., COMSTOCK, R. E., AND HARVEY, P. H. 1949. Estimates of heritability and the degree of dominance in corn. Agron. Four., $4 I, 353-359$.

sMITH, H. H. 1952. Fixing transgressive vigor in Nicotiana rustica. Heterosis, pp. 161-1 74. Ames, Iowa, Iowa Collegiate Press.

WRIGHT, s. I935. The analysis of variance and the correlation between relatives with respect to deviations from an optimum. F. Genet., 30, 243-256. 